\title{
Reactive Spreading in Ceramic/Metal Systems
}

\author{
E. Saiz' ${ }^{1}$ R.M. Cannon ${ }^{1}$ and A.P. Tomsia ${ }^{1}$ \\ 1 Materials Science Division, Lawrence Berkeley National Laboratory, Berkeley, CA 94720 - USA \\ e-mail: esaiz@lbl.gov
}

\begin{abstract}
Résumé - Mouillage réactif des systèmes métaux/céramiques — Le mouillage réactif, dans lequel un élément chimiquement actif est ajouté pour favoriser le mouillage de métaux nobles sur des matériaux non-métalliques, est évalué d'un point de vue mécanique. Les théories pour décrire la formation et la cinétique des marches impliquées dans cette forme de mouillage sont révisées pour mieux souligner les spécificités du mouillage réactif. Ceci inclut l'hydrodynamique, l'adsorption de métaux actifs, y compris les effets de non-équilibre, ainsi que les ondulations de la ligne triple. Tous ces processus peuvent être plus rapides que la nucléation des composés sous certaines conditions.

Cette analyse, complétée par des résultats expérimentaux récents pour des systèmes métaux/céramiques, a conduit à une étude plus poussée de ces conditions sous lesquelles le mouillage intervient avant la formation d'une nouvelle phase en surface. Ce scénario peut être plus général qu'initialement attendu, et constitue peut-être la situation la plus efficace pour améliorer le mouillage. Cette approche fournit ainsi une meilleure compréhension des faibles vitesses de mouillage, ainsi que des hystérèses observées lors de ces mouillages à haute température.
\end{abstract}

Mots-clés : mouillage réactif, mouillage à haute température, systèmes hybrides, métaux/céramiques.

\begin{abstract}
Reactive Spreading in Ceramic/Metal Systems - Reactive spreading, in which a chemically active element is added to promote wetting of noble metals on nonmetallic materials, is evaluated mechanistically. Theories for the energetics and kinetics of the steps involved in spreading are outlined to permit comparison to the steps in the compound formation that typically accompanies reactive wetting. These include: fluid flow, active metal adsorption, including nonequilibrium effects, and triple line ridging. They can all be faster than compound nucleation under certain conditions.

This analysis plus assessment of recently reported experiments in metal/ceramic systems lead to a focus on those conditions under which spreading proceeds ahead of the actual formation of a new phase. This scenario may be more typical than commonly believed, and perhaps is the most effective situation leading to enhanced spreading. A rationale for the slow spreading rates plus the pervasive variability and hysteresis observed during high-temperature wetting also emerges.

Keywords: reactive spreading, high-temperature wetting, metal/ceramic systems.
\end{abstract}




\section{INTRODUCTION}

Most pure metals (e.g., Pt, $\mathrm{Au}, \mathrm{Ag}, \mathrm{Cu}, \mathrm{Ni}$ ) exhibit obtuse contact angles on higher melting point ceramics (such as $\mathrm{SiC}$, $\mathrm{Si}_{3} \mathrm{~N}_{4}$ or $\mathrm{Al}_{2} \mathrm{O}_{3}$ ) or graphite [1-6], and this hampers their use in applications like brazing, bonding, liquid-phase sintering, or infiltration. This problem can be alleviated by alloying a small amount of a reactive metal (such as $\mathrm{Ti}, \mathrm{V}, \mathrm{Cr}, \mathrm{Zr}, \mathrm{Nb}$, $\mathrm{Hf}$, or even $\mathrm{Al}$ ) into the liquid. These additions can enhance wetting angles [2-4, 7-13], often strongly (Fig. 1). However, there is a great variability on the range of contact angles and spreading velocities measured even in similar systems $[2,10$, 11, 14-19]. Whereas most of the proposed theories focused in the role of the reaction products such as nitrides, silicides that have frequently been found at or near the interface after solidification most of them lack predictive power and a controversy still remains about the mechanisms that control reactive spreading.

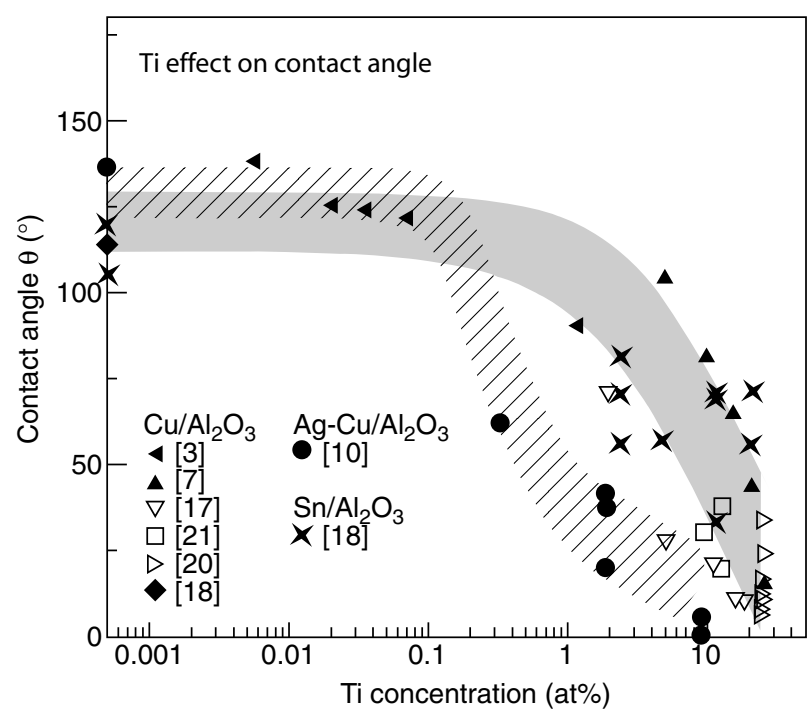

Figure 1

Effects of $\mathrm{Ti}$ additions on wetting angles on $\mathrm{Al}_{2} \mathrm{O}_{3}$ for several metallic alloys. Data for $\mathrm{Cu}-\mathrm{Ti}$ are from $[3,7,17,18,20,21]$; for eutectic $\mathrm{Ag}-\mathrm{Cu}$ from [10]; and for $\mathrm{Sn}$, from [18].

\section{THEORETICAL CONCEPTS}

The present work divides reactive spreading into a series of stages, depending on the spreading time or velocity. These stages include fluid flow, adsorption of active element at any of the several interfaces, triple point ridging, and finally, formation of a new compound at the solid-liquid interface (Fig. 2). During wetting, a system will pass successively through the various stages, but depending upon its properties, the time scale in which any observation is actually accomplished may correspond to only one of them.

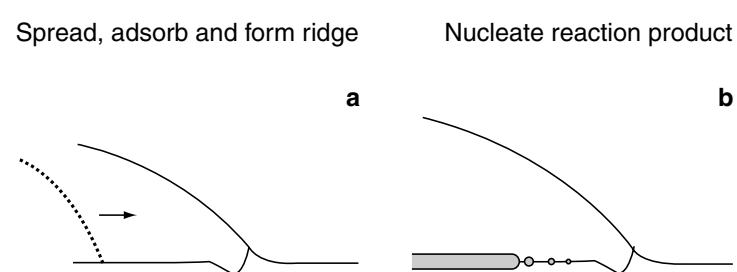

Grow reaction product

Droplet front detaches

c

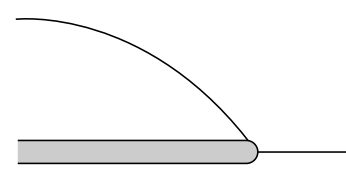

d

Figure 2

Reactive wetting requires several steps from fluid flow, adsorption and triple line ridging, to formation of a phase that may finally cover the solid-liquid interface. With a large nucleation barrier, a time regime exists in which reaction lags the front; contact angles are then dictated by adsorption at the metastable interfaces, and spreading rates can be limited by ridge drag. Occasionally, the front can be dislodged from the reaction product and the sequence repeats.

The idea is to determine which step controls spreading kinetics and what causes the decrease of contact angle. Thus, pertinent stages are briefly considered in terms of the triple junction structure and chemistry, the relevant surface energies that drive wetting, and the mechanisms that control rates.

\section{Fluid Flow}

Numerous theories have analyzed spreading in terms of one fluid displacing another over a rigid and insoluble solid surface. We denote this situation as regime I, with successive spreading regimes corresponding to increasing degrees of concurrent substrate deformation and focus on a liquid/gas combination. The capillary forces drive a homogeneous liquid towards a shape of constant curvature and the contact angle towards the $\theta_{1 D}$ value given by the Young-Dupré equation [22]:

$$
\gamma_{l v} \cos \theta_{1 D}=\gamma_{s v}-\gamma_{s l}
$$

where $\gamma_{l v}$ and $\gamma_{s v}$ are the liquid and solid surface energies, and $\gamma_{s l}$ is the solid/liquid interfacial energy. Other driving forces from hydrostatic pressure gradients will be ignored here. Wetting hysteresis for advancing and receding fronts is usually attributed to morphological or chemical inhomogeneities in the substrate, or to the fact that for contact 
angles close to equilibrium, spreading occurs too slowly to be accurately recorded in practical experiments [23-26].

Dynamic wetting has been analyzed both from the perspectives of continuum mechanics (hydrodynamics) [2426] and microscopic or molecular mechanisms [23, 27, 28]. Hydrodynamical analyses presume that the main force retarding spreading is the viscous impedance, although uncertainty persists regarding the proper flow conditions near the junction [24-26]. Microscopic analyses attribute the mechanisms controlling spreading to atomic dynamics at the triple line. Several have been proposed, including: adsorption-desorption, surface diffusion, evaporationcondensation, molecular reorientation and viscoelastic deformation [23].

Because liquid metals typically have surface energies one to two orders of magnitude above those of organic liquids with similar viscosity, the hydrodynamic analysis predicts that for a similar driving force, metals should spread faster. However, the few dynamic data for high-temperature materials do not corroborate this, although the highest reported velocities are similar $[15,16]$. The fact that most of the recorded spreading velocities for high-temperature systems are slower than expected from the hydrodynamical analysis suggests that microscopic mechanisms may be limiting over a wider range of angles than for simple lowtemperature liquids.

\section{Adsorption Control}

Equilibrium in multicomponent systems requires that interfaces develop an equilibrium level of adsorption by diffusion among all the phases. The effects of adsorption on equilibrium interfacial energies can be described by the Gibbs absorption isotherm [29]. The equilibrium adsorption levels are dictated by the activities, $a_{i}$, of the components in the environment and appear or disappear reversibly with creation or loss of interfacial area. The active metals commonly added to improve wetting on refractory ceramics usually have high surface energies and it is hard to see how an alloy containing a low fraction of such an element could bring $\theta$ far below $90^{\circ}$ without strong adsorption at the metaloxide interface. Adsorption may also occur at the other interfaces and is relevant both for unreacted interfaces and those with reaction phases.

In a model proposed by the authors, the adsorption reactions are treated as energetic precursors of bulk reactions [18]. Elements that strongly enhance wetting in metal-oxide systems typically can react with several types of compounds (e.g., metallic and ionic) and are often multivalent. Thus, they seem likely to adsorb at interfaces, being simultaneously bonded to two differing condensed phases. In addition, metal-oxygen complexes could favorably adsorb on either the oxide surface or liquid.
The effect of small additions of reactive element on the liquid viscosity should be limited. So the simplest hydrodynamic theory does not predict a strong variation of spreading velocities for a given $\left(\theta-\theta_{1 D}\right)$ from adding reactive elements that adsorb. In the microscopic analysis, the reactive element-substrate interaction contains the important parameters. If adsorbing the reactive element is the kinetically limiting step and its interaction with the substrate is stronger than that of the solvent, a decrease in the dewetting velocity of receding fronts can be expected. Whereas, a relatively smaller effect is anticipated for advancing. More complex situations can exist-for example, when adsorbing a multicomponent complex involves cooperative motion or steric constraints or when attachment is limited by ledge motion (e.g., to expedite reconstruction). For rapid spreading or for very dilute solutions transport of the adsorbate from the bulk liquid to the interfaces could be an issue.

During rapid spreading several nonequilibrium situations can exist [2, 24, 30, 31]. For example, when the primary source of adsorbate for the solid surface is the liquid itself (solvent or solute), but spreading is too rapid for equilibrium levels to actually develop on the surface ahead of the liquid $[24,31]$. An extreme situation is when the surface directly ahead is clean, termed dry spreading [24]. Substituting the energy for a pure surface, $\gamma_{s v}^{0}\left(\gamma_{s v}^{0} \geq \gamma_{s v}\right)$, into Equation (1), in conjunction with equilibrium interface and liquid energies, would often imply low values of the angle, $\theta_{1 D}^{\mathrm{dry}}$. In contrast, a receding drop would tend to leave the adsorbate already established under the liquid. Leaving too much adsorbate would effectively increase the solid surface energy, inhibiting retraction.

The critical spreading velocity above which adsorption at the triple line could not accompany spreading and influence the driving force via reduced $\gamma_{s l}$ can be estimated as:

$$
v_{c a}=v_{c a}^{*}=\frac{6 \alpha X_{R} D_{\mathrm{liq}}}{a}
$$

where $D_{\text {liq }}$ is the diffusivity in the liquid, $a$ the atom spacing for the solid, $X_{R}$ the adsorbate fraction in the liquid, and $\alpha(<1)$ a sticking coefficient that describes the chance that an atom jumping from the liquid would attach to the surface at the triple line. Much lower velocities would be needed to permit spreading of adsorbate onto the surface ahead or for a receding liquid to remove adsorbate.

Adsorption is believed to be responsible for the large reductions of contact angle achieved in several metal/ceramic systems by adding small quantities of a reactive element to the liquid without forming a reaction product at the interface. It has been demonstrated that adsorption reactions involving $\mathrm{O}$ promote lower contact angles for $\mathrm{Ni}$ or $\mathrm{Cu}$ on $\mathrm{Al}_{2} \mathrm{O}_{3}[18$, 32] and references therein and recent work indicate that even lower contact angles can result from adsorption for $\mathrm{Sn}-\mathrm{Ti}$ and $\mathrm{Cu}-\mathrm{Nb}$ alloys on $\mathrm{Al}_{2} \mathrm{O}_{3}$ [19]. Nonequilibrium adsorption could be the cause for the low angles achieved when a liquid 
metal is introduced onto a solid of another pure metal (rather than using a pre-equilibrated solid). In this case extensive spreading toward $\theta$ values well below equilibrium [33] has been observed.

\section{Ridge Formation}

In many low-temperature systems (e.g., organic liquids on most ceramics or metals) the vertical component of the surface tension induced force at the triple junction is resisted by elastic distortions of the solid. It is then accurate to describe the substrate as ideally rigid and insoluble. However, for molten metals or oxides exposure temperatures are typically $\geq(0.2-0.5) T_{m}^{s}\left(T_{m}^{s}\right.$ being the substrate melting point), which will allow some local diffusion or solution/ precipitation of the solid atoms. Then, attaining equilibrium at the junction requires motion of the triple line both horizontally and vertically [34-36] (two-dimensional, 2D case) which leads to two independent relations:

$$
\frac{\sin \phi_{s}}{\gamma_{l v}}=\frac{\sin \phi_{l}}{\gamma_{s v}}=\frac{\sin \phi_{v}}{\gamma_{s l}}
$$

where $\phi_{s}, \phi_{l}$ and $\phi_{v}$ are the equilibrium dihedral angles in the solid, liquid and vapor phases, respectively. Under such conditions, at a certain point a small ridge will develop at the triple junction as a result of atomic migration near the contact line to satisfy Equation (3) locally. The triple junction will remain attached to the ridge unless a sudden perturbation drives the macroscopic contact angle outside a stability range that depends on the ridge orientation, causing the wetting front to break away [35, 37]. The ridge will evolve and propagate until complete equilibrium is attained. Equilibrium involves constant chemical potential shapes (i.e., constant curvature for isotropic systems) [29]. Although attaining full equilibrium may take an impossibly long time, the small ridge can be highly influential.

Recently, it has been recognized that small triple line ridges can control spreading rates and hysteresis for hightemperature systems [35]. A parallel between triple line ridging and the Mullins theory for grain boundary grooving $[38,39]$ has been established. Essential aspects of small-ridge behavior have been determined for situations wherein interfacial diffusion is rate controlling [35]. A time scale exists in which a ridge is very small compared with the radius of curvature for the liquid, $h / R<<0.1$ and can be carried by a moving front. In this situation, denoted regime II spreading, the capillary forces drive the macroscopic $\theta$ toward a value very near that satisfying Young's equation, with a driving force approximated by that for regime I $\left(\gamma_{l v}\left(\cos \theta_{1 D}-\cos \theta\right)\right)$ but with spreading kinetics dictated by the rate at which the attached ridge moves [35].

When the ridge movement is controlled by interfacial diffusion, two steady-state conditions (corresponding to advancing and receding fronts) exist in which a liquid front can move with constant velocity attached to a ridge of constant height $[35,39]$. For macroscopic contact angles within the range delimited by the associated angles $\theta_{s s}^{\text {rec }}$ and $\theta_{s \mathrm{~s}}^{\mathrm{adv}}$, the liquid front will remain attached to a ridge and decelerate, while the ridge grows faster as the angle sweeps toward $\theta_{1 D}$. A junction moving on a smooth surface should form a ridge spontaneously by diffusion once $\theta$ is within the range delimited by the steady-state solutions, and sharp perturbations (such as scratches) may act as incipient ridges. When $\theta$ is outside the growth range, any ridge attached to a junction would shrink during spreading; such a liquid spreading on a smooth surface would have no tendency to form a ridge and would resist being pinned upon passing a ridge-like asperity. As $\left|\theta-\theta_{1 D}\right|$ diminishes, the front should be increasingly resistant to break away from a ridge triggered by a disturbance or change in liquid volume [35, 37].

For a drop spreading stably in regime II, the extent of ridge growth should depend on the drop size and change in angle and it is independent of temperature. The velocities scale with the controlling diffusivity, leading to faster spreading and ridge growth at higher temperature [35]. However, a condition exists wherein a liquid can spread on a flat surface quickly enough to suppress initiation of ridge growth even if $\theta_{s s}^{\text {rec }}<\theta<\theta_{s s}^{\text {adv }}$. Diffusional fluxes are limited by the actual atomic jump frequency rather than being virtually infinite as $h \rightarrow 0$. The critical spreading velocity $\left(v_{c r}\right)$ beyond which ridge formation is impossible, because the jump frequency becomes too slow compared to the spreading velocity and the first atomic sized ridge cannot form at the triple junction can be estimated as:

$$
v_{c r}=\frac{6 D_{s l}}{a}
$$

where $a$ is a jump distance and $D_{s l}$ the diffusion coefficient at the solid/liquid interface. In the transitional temperature regime, a fast moving front (in regime I) could sweep into the ridge-growth range until the driving force $\left(\theta-\theta_{1 D}\right)$ is diminished enough that the slow spreading allows ridge formation. The requisite distance traveled before ridge initiation would shrink, and so the extent of ridge growth while approaching $\theta_{1 D}$ would increase with rising temperature.

Ridges have been found in several systems. The heights span from $10 \mathrm{~nm}$ for $\mathrm{Cu}$ on $\mathrm{Al}_{2} \mathrm{O}_{3}$ (Fig. 3), to $0.2 \mu \mathrm{m}$ for $\mathrm{Ni}$ on $\mathrm{Al}_{2} \mathrm{O}_{3}$, to $70 \mu \mathrm{m}$ for silicate liquids on Co at $99 \%$ of $T_{m}$ for the Co [35]. The shapes of ridges with sizes up to $\sim 1 \mu \mathrm{m}$ indicate that the kinetics are dictated by diffusion at the interface or within the liquid [35]. For liquid $\mathrm{Cu}$ drops on sapphire, advancing and receding fronts approach a common angle after many minutes (involving $v \sim 10^{-7}-10^{-6} \mathrm{~m} / \mathrm{s}$ ), which indicates that the ridges are small and that spreading occurs under regime II conditions. Thus, the final angle is held to satisfy Equation (1). 


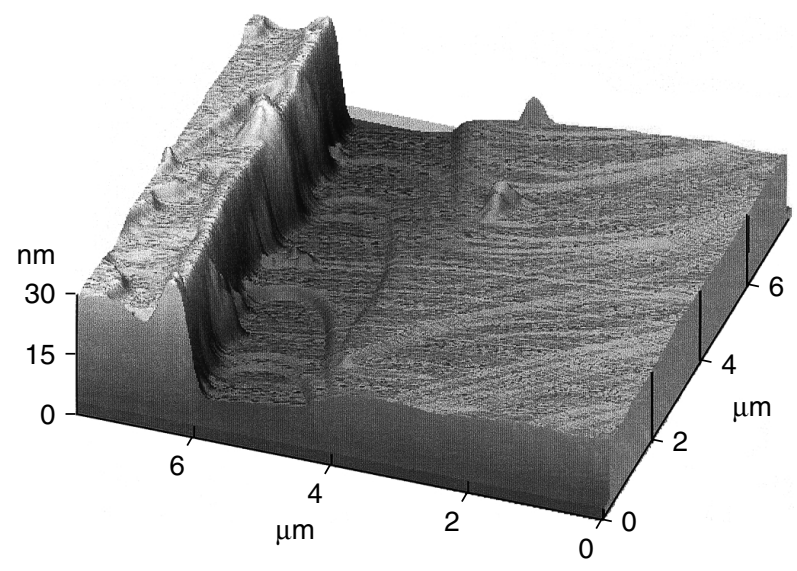

Figure 3

AFM image of ridge that developed at the triple junction of a receding $\mathrm{Cu}$ drop on sapphire after $150 \mathrm{~min}$ at $1150^{\circ} \mathrm{C}$ in gettered Ar.

Within the angle interval for ridge-controlled spreading, there is no unique wetting velocity for each dynamic contact angle, but rather a broad range of velocities that depend inversely on the ridge height. That height depends on the size of the perturbation that originated it and the contact angle at which it actually initiated. This could be one source of the wide variability in spreading velocities recorded in hightemperature systems for similar liquids. The spreading in regime I can be far faster than in regime II. For an advancing front $v_{c a}^{*} / v_{c r}=\alpha X_{R} D_{\text {liq }} / D_{s l}$ from Equations (2) and (4). For the range of $\omega D_{s l}$ quoted just above, and taking $\omega=1 \mathrm{~nm}$ and $D_{\text {liq }}=10^{-9} \mathrm{~m}^{2} / \mathrm{s}, D_{\text {liq }} / D_{s l} \sim 10^{6}-1$, with increasing temperature. Hence, rapid regime I type spreading with adsorption at the interface being created would be likely at more moderate substrate temperatures, even for dilute adsorbates, unless $\alpha$ is small. At higher temperature, once $v_{c a} / v_{c r}<1$, ridging will readily initiate at $\theta \rightarrow \theta_{s s}$ and rapidly impede spreading.

\section{Reaction Phase Formation}

Frequently, a supersaturated species from a liquid can react with a solid to form a new phase more or less continuously along the original solid/liquid interface. Although the presence of a reaction product would undoubtedly affect the spreading rates and ultimate contact angle, such phases are typically seen postmortem, without knowing when they formed with respect to spreading. Several distinct situations may exist (Figs. 2 and 4), depending upon the rates of nucleation and continued reaction.

With slow nucleation a supersaturated fluid can spread leaving behind a metastable interface with well-defined properties, which may include low $\gamma_{s l}$ owing to adsorption of reactant (Fig. 2a). The rapid fluid flow must accommodate adsorption to actually reduce $\gamma_{s l}$ just behind the triple junction. This could yield a transient situation (with potential for later liquid retraction), wherein a very low $\gamma_{s l}$ develops and is followed by an increase of $\gamma_{s l}$ as growth of the reaction phase at places along the interface diminishes the supersaturation of a chemically active species, $R$.

If a new compound can nucleate rapidly enough, several other configurations might be possible (Fig. 4). In one, the liquid wets to the edge of the reaction layer but not onto the solid ahead (Figs. $2 c$ and 4). The reaction layer and liquid could then extend together, as limited by reaction kinetics, and the apparent contact angle would decrease. Limited by counter-diffusion of reactants across the tip of the reaction layer, spreading would then be comparatively slow for more than nanometer-thick layers. Alternatively, the compound may extend beyond the liquid front (Fig. 4). The drop would then seek a shape dictated by surface and interfacial $\gamma$ 's for the reaction product. In a frequently observed variant the reaction product is porous and contains an interconnected liquid, through which the reactant can move [11, 31, 40].

A major issue is, therefore, whether the new phase can form at the triple junction at the same time that the liquid front spreads. A limiting situation is attained if the liquid spreads so quickly that not enough time exists to nucleate the reaction product at the substrate near the spreading front. The critical velocity can be roughly estimated as $a^{3} I_{s}$; where $I_{s}$ is the steady-state frequency for nucleating a new phase, $\beta$, from the liquid at the substrate-liquid interface [41, 42]. This velocity is:

$$
\begin{gathered}
v_{c n}=6\left(\frac{D^{*}}{a}\right) \exp \left[-\frac{16 \pi \gamma_{\beta l}^{3}}{3\left(\Delta G_{v}\right)^{2} k T} f\left(\theta_{1}\right)\right] \\
f\left(\theta_{1}\right)=\frac{\left(1+\cos \theta_{1}\right)\left(1-\cos \theta_{1}\right)^{2}}{4}
\end{gathered}
$$
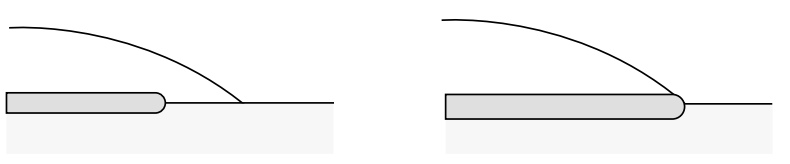

$\theta \rightarrow \theta_{1 D}$ (metastable?)

$v \rightarrow$ fluid flow and adsorption or ridging

\section{$\theta \rightarrow$ ?}

$v \rightarrow$ reaction product growth $(\mathrm{D} / \mathrm{h})$
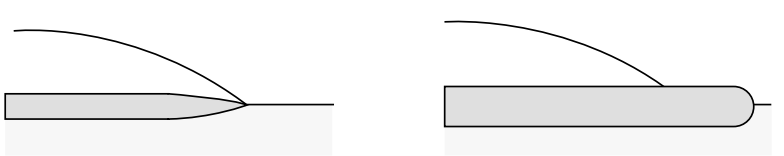

$\theta \rightarrow$ ?

$\theta \rightarrow \theta_{1 D}$ (on reaction product)

$v \rightarrow ?$

$v \rightarrow$ ridging and roughness

Figure 4

Possible triple line configurations, with their corresponding wetting driving forces and spreading kinetics. 
where $\gamma_{\beta l}$ is the interfacial energy between $\beta$ (the reaction product) and the liquid, $\Delta G_{v}$ the free energy change driving reaction, $D^{*}$ the local diffusivity controlling attachment to an embryo, and $N_{s}$ the areal site density for nuclei in the system. The factor $f\left(\theta_{1}\right)$ approximates the reduction in nucleus energy if the new phase partially wets the interface, where the wetting angle of the new $\beta$ phase on the interface $\theta_{1}$ (Fig. 5) is a key determinant. If $\theta_{1} \rightarrow 0$, the barrier to nucleation vanishes. This underestimates $v_{c n}$ by a factor $<A / a^{2}, A$ being the area of interface over which spreading occurs. However, for rapid spreading, a further adjustment for the transient nucleation rates being slower than for Equation (5) would be partially compensating.

In cases of interest, adsorption at the original interface would lower $\gamma_{s l}$ and promote wetting of the liquid onto the substrate. The extent of further adsorption as the activity of the reactive element $R\left(a_{R}\right)$ increases to and beyond the equilibrium level to form a new phase (Fig. 5) is germane. When $\theta_{1} \rightarrow 0$, upon approaching the solubility limit, a smooth transition occurs, energetically, from monolayer adsorption through some layers of multilayer adsorption to a reaction product that fully wets the original interface $\left(\theta_{1}=0\right)$. In contrast, where only monolayer adsorption is favorable, the new phase does not fully wet the interface and so some supersaturation of $R$ can occur without nucleation. In addition, a lower sticking probability applies for reactive element attachment to form the nucleus than to form the adsorbate $\left(v_{c n}<<<v_{c a}\right)$. In this instance, the metastable interfacial energy can decrease to very low levels (Fig. 5), giving much lower wetting angles, $\theta$, for the liquid on the substrate than would apply after depletion of $R$ back to the solubility limit. Note that the partial wetting condition, $\theta_{1}>0$, alludes to isolated particles of reaction product, not to the polycrystalline layer that can eventually cover the interface (metastably) during extensive reaction.

Comparing Equations (4) and (5) shows that the highest velocity that would allow nucleation at the spreading front is reduced from the critical adsorption velocity, $v_{c a}^{*}$, primarily by the factor, $\exp \left\{-\left[16 \pi \gamma_{\beta l}{ }^{3} / 3\left(\Delta G_{v}\right)^{2} k T\right] f\left(\theta_{1}\right)\right\}$. For supersaturations below the critical level to bring $\theta_{1}=0$, this can be many orders of magnitude less than unity. Then $\left(v_{c a}>>>v_{c n}\right)$, a liquid in regime I could spread toward a low metastable contact angle, $\theta_{1 D}$, because it leaves directly behind a metastable interface with low solid/liquid interfacial energy. However, for a liquid front spreading at a lower velocity limited by ridge drag (regime II), as the velocity drops with larger ridge heights, there would increasingly be time to also permit adsorption on the surface ahead of the triple line and nucleation at the interface.

Additions of $\mathrm{Ti}$ to $\mathrm{Cu}$ and $\mathrm{Cu}-\mathrm{Ag}$ eutectic liquids enhance wetting on oxides. In many cases, reaction products form extensively near the interface; the details depend upon the Ti level [10]. The contact angles vary notably, even for similar samples; with 2 at $\% \mathrm{Ti}$, angles on various samples

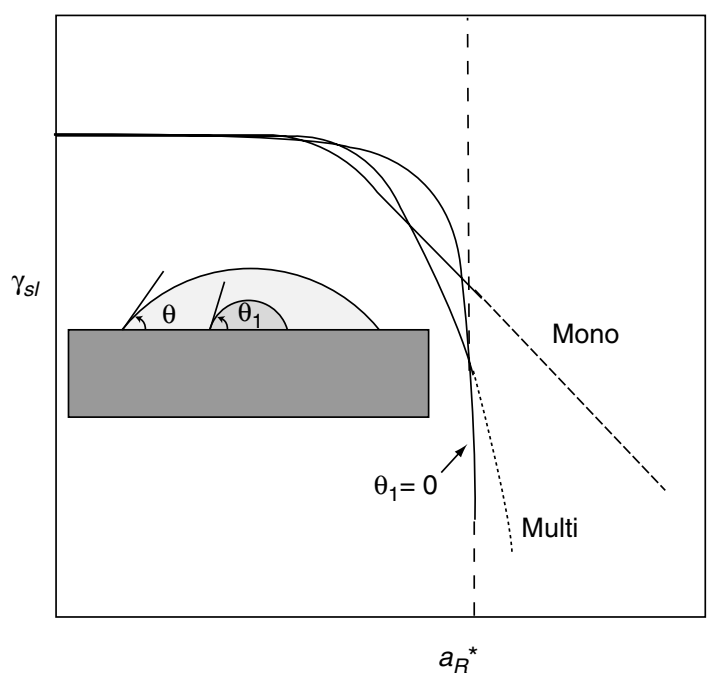

Figure 5

Sketch showing how the interfacial energy varies for three different forms of interfacial adsorption. The three situations will exhibit markedly different barriers for heterogeneous nucleation of a new phase at the interface.
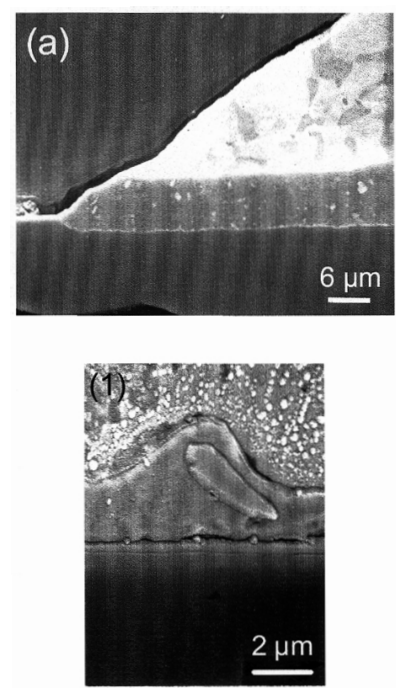

Figure 6
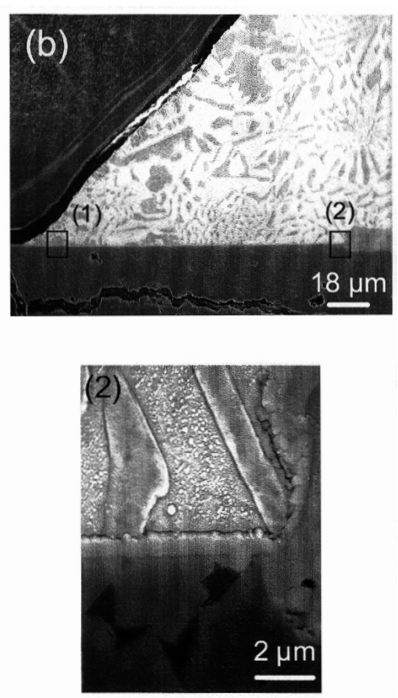

SEM images of cross-sections of two wetting specimens of eutectic $\mathrm{Ag}-\mathrm{Cu}+1.9 \% \mathrm{Ti} / \mathrm{Al}_{2} \mathrm{O}_{3}$ after annealing at $1000^{\circ} \mathrm{C}$ for 1 hour in Ar. In (a), the drop on sapphire spread to $\theta \sim 20^{\circ}$, and a uniform layer of $\mathrm{TiO}$-rich reaction product formed at the interface. The other sample (b), made with $96 \%$ $\mathrm{Al}_{2} \mathrm{O}_{3}$, is revealing; for this, the liquid was arrested at a higher angle. A uniform layer of $\mathrm{TiO}$ formed, but then the front dislodged and advanced further, and again subsequently formed thin layers of reaction product at the interface.

of sapphire and commercial $\mathrm{Al}_{2} \mathrm{O}_{3}(99.8 \%$ and $96 \%)$ spanned $\theta \sim 20-40^{\circ}$. After two hours, the $2 \%$ samples exhibit a layer of $\mathrm{TiO}$ that is thick enough to account for most of the Ti (Fig. 6). Typically, a uniform layer extends to the edge of 
the contact (Fig. 6), a geometry seemingly attributable to the reaction and liquid spreading together. However, if that were the case, the spreading rates that correspond to the concurrent growth rate of the reaction product would be far slower than observed. In contrast, in the sample in which the front had arrested at a higher angle (Fig. 6), the reaction product is much thinner near the triple line and the sequence seems in agreement with the mechanism depicted in Figure 2. The liquid spreads ahead of the reaction front, with $\theta_{1 D}$ dictated by the metastable $\gamma_{s l}$, until a triple line ridge becomes big enough to essentially arrest spreading at $\theta>\theta_{1 D}$. Subsequently, reaction product will form rather uniformly under the drop. If the front is dislodged from this position, some driving force for further advance still remains despite the depletion of reactive element. Hence, the front will move ahead until it is virtually re-arrested by a growing ridge.

\section{CONCLUDING REMARKS}

Reactive spreading involves several, sometimes competitive, processes, with differences among them dictating evolution along different paths. We divide the process into a series of stages: liquid flow, adsorption of reactive element, ridging, nucleation and growth of the reaction phase (Fig. 2). The objective is to determine the structure and composition of the triple junction (Fig. 4) for each stage in order to identify what drives the decrease of contact angle, as well as which process controls the spreading kinetics.

The primary question for a given system is whether adsorption drives spreading prior to forming a new phase or whether the phase forms first and spreads with, or even ahead of, the front. A second concern is what controls rates and arrests spreading.

Several observations suggest that in many reactive cases, a finite nucleation barrier to forming the reaction product does exist. This implies that spreading to low contact angles can be driven by adsorption at the interface either without, or prior to, forming a reaction phase whereas the observed slow or erratic spreading rates are dictated by migration or pinning of a triple point ridge.

\section{ACKNOWLEDGMENTS}

This work was supported by Director, Office of Energy Research, Office of Basic Energy Sciences, Materials Sciences Division of US Department of Energy under Contract No. DE-AC03-76SF00098.

\section{REFERENCES}

1 Chatain, D., Rivollet, I. and Eustathopoulos, N. (1986) Thermodynamic Adhesion in Nonreactive Liquid MetalAlumina Systems. Journal de Chimie Physique et de PhysicoChimie Biologique, 83, 9, 561-567.
2 Naidich, Y.V. (1981) The Wettability of Solids by Liquid Metal. Progress in Surface and Membrane Sciences, 14, 353484.

3 Kurkjian, C.R. and Kingery, W.D. (1956) Surface Tension at Elevated Temperatures, III. Effect of $\mathrm{Cr}$, In, Sn, and Ti on Liquid Ni Surface Tension and Interfacial Energy with $\mathrm{Al}_{2} \mathrm{O}_{3}$. J. Phys. Chem., 60, 961-963.

4 Humenik Jr., M. and Kingery, W.D. (1954) Metal-Ceramic Interactions: III. Surface Tension and Wettability of MetalCeramic Systems. J. Amer. Ceram. Soc., 37, 1, 18-23.

5 Li, J.G. (1992) Wetting and Interfacial Bonding of Metals with Ioncovalent Oxides. J. Amer. Ceram. Soc., 75, 11, 31183126.

6 Stoneham, A.M., Dufy, D.M. and Harding, J.H. (1993) in Designing Ceramic Interfaces II: Understanding and Tailoring Interfaces for Coating, Composite and Joining Applications, Peteves, S.D. (ed.), Committe of European Communities, Luxembourg, 573-582.

7 Nicholas, M.G., Valentine, T.M. and Waite, M.J. (1980) The Wetting of Alumina by Copper Alloyed with Titanium and Other Elements. J. Mat. Sci., 15, 9, 2167-2206.

8 Nicholas, M.G. and Mortimer, D.A. (1985) Ceramic/Metal Joining for Structural Applications. Mat. Sci. Tech., 1, 9, 657-665.

9 Scott, P.M., Nicholas, M. and Dewar, B. (1975) The Wetting and Bonding of Diamonds by Copper-Base Binary Alloys. J. Mat. Sci., 10, 11, 1833-1840.

10 Loehman, R.E. and Tomsia, A.P. (1992) Reactions of Ti and $\mathrm{Zr}$ with $\mathrm{AlN}$ and $\mathrm{Al}_{2} \mathrm{O}_{3}$. Acta Metal. Mater., 40, S75-83.

11 Loehman, R.E. and Tomsia, A.P. (1994) Wetting and Joining of Mullite Ceramics by Active-Metal Braze Alloys. J. Amer. Ceram. Soc., 77, 1, 271-274.

12 Eustathopoulos, N., Chatain, D. and Coudurier, L. (1991) Wetting and Interfacial Chemistry in Liquid Metal-Ceramic Systems. Mat. Sci. Eng., A135, 83-88.

13 Nogi, K. (1993) Transactions of the Japanese Welding Research Institute, 22, 183.

14 Ambrose, J.C., Nicholas, M.G. and Stoneham, A.M. (1992) Dynamics of Braze Spreading. Acta Metal. Mater., 40, 10, 2483-2488.

15 Voitovitch, R., Mortensen, A. Hodaj, F. and Eustathopoulos, N. (1999) Diffusion-Limited Reactive Wetting: Study of Spreading Kinetics of $\mathrm{Cu}-\mathrm{Cr}$ Alloys on Carbon Substrates. Acta Mater., 47, 4, 1117-1128.

16 Grigorenko, N., Poluyanskaya, V., Eustathopoulos, N. and Naidich, Y. (1998) Kinetics of Spreading of Some Metal Melts over Covalent Ceramic Surfaces, in Interfacial Science of Ceramic Joining, Bellosi, A., Kosmac, T. and Tomsia, A.P. (eds.), Kluwer Academic Publishers, Dordrecht, The Netherlands, 57-68.

17 Kritsalis, P., Coudurier, L. and Eustathopoulos, N. (1991) Contribution to the Study of Reactive Wetting in the CuTi/ $/ \mathrm{Al}_{2} \mathrm{O}_{3}$ System. J. Mat. Sci., 26, 12, 3400-3408.

18 Saiz, E., Cannon, R.M. and Tomsia, A.P. (2000) Reactive Spreading: Adsorption Ridging and Compound Formation. Acta Mater. (in press).

19 Naidich, Y.V., Zhuravljov, V.S. and Erumina, N.I. (1990) Wetting of Rare-Earth Element Oxides by Metallic Melts. J. Mat.Sci., 25, 4, 1895-1901.

20 Meier, A., Chidambaram, P.R. and Edwards, G.R. (1995) Generation of Isothermal Spreading Data and Interfacial Energy Data for Liquid Reactive Metals on Ceramic Substrates: the Copper-Titanium/Alumina System. J. Mat. Sci., 30, 15, 3791-3798. 
21 Li, J.G. (1992) Kinetics of Wetting and Spreading of Cu-Ti Alloys on Alumina and Glassy Carbon Substrates. J. Mater. Sci. Let., 11, 1551-1554.

22 Adamson, A.W. (1982) Physical Chemistry of Surfaces, 4th ed., John Wiley \& Sons, New York.

23 Blake, T.D. (1993) Dynamic Contact Angles and Wetting Kinetics, in Wettability, Berg, J.C. (ed.), Marcel Dekker, New York, 251-310.

24 De Gennes, P.G. (1985) Wetting: Statics and Dynamics. Rev. Mod. Phys., 57, 3 (pt. 1), 827-863.

25 Davis, S.H. (1983) Contact-Line Problems in Fluid Mechanics. Transactions of the ASME. Journal of Applied Mechanics, 50, 4B, 977-982.

26 Kistler, S.F. (1993) Hydrodynamics of Wetting, in Wettability, Berg, J.C. (ed.), Marcel Dekker, New York, 311430.

27 Blake, T.D. and Haynes, J.M. (1969) Kinetics of Liquid/Liquid Displacement. J. Coll. Interf. Sci., 30, 3, 421.

28 Ruckenstein, E. and Dunn, C.S. (1977) Slip Velocity During Wetting of Solids. J. Coll. Interf. Sci., 59, 1, 135-138.

29 Gibbs, J.W. (1931) Collected Works, Vol. I., Longmans, New York.

30 Aksay, I.A., Hoge, C.E. and Pask, J.A. (1974) Wetting under Chemical Equilibrium and Non-Equilibrium Conditions. J. Phys. Chem., 78, 12, 1178-1183.

31 Cannon, R.M., Saiz, E., Tomsia, A.P. and Carter, W.C. (1995) Reactive Wetting Taxonomy, in Materials Research Symposium Proceedings: Structure and Properties of Interfaces in Ceramics, Bonnell, D.A., Rühle, M. and Chowdhry, U. (eds.), MRS, Warrendale, Pennsylvania, 279292.

32 Ghetta, V., Fouletier, J. and Chatain, D. (1996) Oxygen Adsorption Isotherms at the Surfaces of Liquid $\mathrm{Cu}$ and
$\mathrm{Au}-\mathrm{Cu}$ Alloys and their Interfaces with $\mathrm{Al}_{2} \mathrm{O}_{3}$ Detected by Wetting Experiments. Acta. Mater., 44, 5, 1927-1936.

33 Sharps, P.R., Tomsia, A.P. and Pask, J.A. (1981) Wetting and Spreading in the $\mathrm{Cu}-\mathrm{Ag}$ System. Acta Metal., 29, 5, 855865.

34 Bikerman, J.J. (1959) Use of Hysteresis of Wetting for Measuring Surface Tension. J. of Phys. Chem., 62, 12, 15341536.

35 Saiz, E., Tomsia, A.P. and Cannon, R.M. (1998) Ridging Effects on Wetting and Spreading of Liquids on Solids. Acta Mater., 46, 7, 2349-2361.

36 Shanahan, M.E.R. and Carre, A. (1995) Viscoelastic Dissipation in Wetting and Adhesion Phenomena. Langmuir, 11, 4, 1396-1402.

37 Saiz, E., Cannon, R.M. and Tomsia, A.P. (2000) Triple Line Ridging and Attachment in High Temperature Wetting. Scripta Mater. (in press).

38 Mullins, W.W. (1957) Theory of Thermal Grooving. J. Appl. Phys., 28, 3, 333-339.

39 Mullins, W.W. (1958) The Effect of Thermal Grooving on Grain Boundary Motion. Acta Metal., 6, 414-427.

40 Saiz, E. and Tomsia, A.P. (1998) Kinetics of Metal-Ceramic Composite Formation by Reactive Penetration of Silicates with Molten Aluminium. J. Amer. Ceram. Soc., 81, 9, 23812393.

41 Turnbull, D. (1956) Solid State Physics, Academic Press, New York.

42 Christian, J.W. (1975) Chap. 10, in Theory of Transformations in Metals and Alloys, Pergamon Press, New York.

Final manuscript received in September 2000 